\title{
An Interprofessional Clinical Placement in a Primary Healthcare Setting: A Pilot Study
}

\author{
Christina Aggar \\ Southern Cross University, christina.aggar@scu.edu.au \\ Beth Mozolic-Staunton \\ Southern Cross University, beth.mozolic-staunton@scu.edu.au \\ Renee Joyce Lovi \\ Southern Cross University, renee.lovi@scu.edu.au \\ Maggie Scorey \\ Southern Cross University, maggie.scorey@scu.edu.au \\ Melissa Kemp \\ Southern Cross University, melissa.kemp@scu.edu.au
}

See next page for additional authors

Follow this and additional works at: https://nsuworks.nova.edu/ijahsp

Part of the Occupational Therapy Commons, Other Medicine and Health Sciences Commons, and the Public Health and Community Nursing Commons

\section{Recommended Citation}

Aggar C, Mozolic-Staunton B, Lovi RJ, Scorey M, Kemp M, Walker T, et al. An Interprofessional Clinical Placement in a Primary Healthcare Setting: A Pilot Study. The Internet Journal of Allied Health Sciences and Practice. 2020 Jan 01;18(1), Article 6.

This Manuscript is brought to you for free and open access by the College of Health Care Sciences at NSUWorks. It has been accepted for inclusion in Internet Journal of Allied Health Sciences and Practice by an authorized editor of NSUWorks. For more information, please contact nsuworks@nova.edu. 


\title{
An Interprofessional Clinical Placement in a Primary Healthcare Setting: A Pilot Study
}

\begin{abstract}
Purpose: Internationally, and in Australia, interprofessional education (IPE) is becoming typical in primary healthcare delivery and is core to delivering patient-centred care. It is essential that primary healthcare education develop interprofessional capacity in order to produce a skilled workforce. An IPE clinical placement for undergraduate health students was developed and piloted in primary healthcare settings. The aim of this study was to evaluate the impact of the IPE clinical placement in a primary healthcare setting on students' perceptions of interprofessional education. Method: A pre-post placement validated questionnaire $(n=19)$ indicated overall perceptions of IPE significantly increased over the course of the IPE clinical placement. Results: There was a significant increase in competency and autonomy and understanding of roles over time. There was no significant increase in the reported perception of need for interprofessional cooperation, however there was a significant increase in actual interprofessional cooperation. Conclusion: This was a successful pilot program that warrants further development and research to include longer-term follow up of students' perceptions towards IPE and analyze whether collaboration and teamwork skills obtained during the IPE primary healthcare experience are transferrable to future professional practice.
\end{abstract}

\section{Author Bio(s)}

Christina Aggar, RN, BN(Hons), Grad Cert HE, PhD, is a registered nurse with 25 years of clinical and academic experience. Christina's research interests include primary health care, workforce development and clinical skills education. Christina is currently the conjoint Academic Research appointment with Northern NSW LHD and Southern Cross University.

Beth Mozolic-Staunton, OTR, BA Neuroscience/Psychology, Grad Cert HE, MS OccThy, is a paediatric occupational therapist, lecturer and researcher at Southern Cross University. Beth's research interests include health promotion and primary care, early intervention, developmental disability and health professional education.

Renee Lovi, RN, BN, MN, PhD, is a registered nurse, lecturer and researcher at Southern Cross University. Renee's research interests include primary health care, women's health, health promotion and domestic violence. Renee's most recent projects involve curriculum development and the addition of holistic care of trauma related victims.

Maggie Scorey, B(OccThy), Grad Cert Academic Practice, is a registered occupational therapist, lecturer and researcher at Southern Cross University. Maggie's is the professional experience lead for occupational therapy at Southern Cross University. Her clinical interest is in neurosciences and her research interests include practice education and rehabilitation for professional surfers.

Melissa Kemp, B (Sp Path) is a speech pathologist, lecturer and researcher at Southern Cross University. Melissa's current role is the professional experience lead for speech pathology. Her interests include feedback in clinical education, reflective practice, peer learning and building learner and educator capability in clinical practice contexts.

Dr. Tara Walker, RN, MBA, PhD, is the Director of Multidisciplinary Programs at Broken Hill University, Department of Rural Health

Sian Lewis, BA(MEL) is a research assistant for the Organisational Unit, School of Health and Human Sciences. 
Authors

Christina Aggar, Beth Mozolic-Staunton, Renee Joyce Lovi, Maggie Scorey, Melissa Kemp, Tara Walker, and Sian Lewis 


\title{
IITAHSP \\ The Internet Joumnal of Allied Health Sciences and Practice \\ Dedicated to allied health professional practice and education
}

Vol. 18 No. 1 ISSN 1540-580X

\section{An Interprofessional Clinical Placement in a Primary Healthcare Setting: A Pilot Study}

\author{
Christina Aggar ${ }^{1}$ \\ Beth Mozolic-Staunton ${ }^{1}$ \\ Renee Joyce Lovi ${ }^{1}$ \\ Maggie Scorey ${ }^{1}$ \\ Melissa Kemp ${ }^{1}$ \\ Tara Walker ${ }^{2}$ \\ Sian Lewis ${ }^{1}$
}

1. Southern Cross University

2. Broken Hill University

Australia

\begin{abstract}
Purpose: Internationally, and in Australia, interprofessional education (IPE) is becoming typical in primary healthcare delivery and is core to delivering patient-centred care. It is essential that primary healthcare education develop interprofessional capacity in order to produce a skilled workforce. An IPE clinical placement for undergraduate health students was developed and piloted in primary healthcare settings. The aim of this study was to evaluate the impact of the IPE clinical placement in a primary healthcare setting on students' perceptions of interprofessional education. Method: A pre-post placement validated questionnaire $(n=19)$ indicated overall perceptions of IPE significantly increased over the course of the IPE clinical placement. Results: There was a significant increase in competency and autonomy and understanding of roles over time. There was no significant increase in the reported perception of need for interprofessional cooperation, however there was a significant increase in actual interprofessional cooperation. Conclusion: This was a successful pilot program that warrants further development and research to include longerterm follow up of students' perceptions towards IPE and analyze whether collaboration and teamwork skills obtained during the IPE primary healthcare experience are transferrable to future professional practice.
\end{abstract}

Keywords: interprofessional education; allied health, nursing, primary healthcare, clinical placement 


\section{INTRODUCTION}

Interprofessional education (IPE), collaboration, and teamwork are becoming standard practice in health delivery and are core to delivering patient-centred care. ${ }^{1}$ The global challenge of addressing multimorbidity and health disparity, and facilitating behaviour change and self-management strategies is changing the role of health care professionals and clinical practice. ${ }^{2}$ Interprofessional education enables students to approach patient care using different professional lenses, providing the opportunity to deliver quality patient care. ${ }^{3}$ Research has shown that patients benefit from IPE, through improved collaboration, patient satisfaction with shorter hospital stays, improved rates of mortality and morbidity, and quality of care. ${ }^{1}$

Education programs to develop workforce capacity in key aspects of interprofessional practice including teamwork and collaboration skills are required to meet the future health care demands. ${ }^{1}$ Interprofessional education is recognized as a key principle underpinning the design and delivery of health professional education and training programs in Australia. ${ }^{4}$ However, in Australia, IPE is not standardized and requires a more organized and planned approach. ${ }^{5}$ Consequently, and in order to provide a framework for IPE, the accreditation authorities of the regulated health professions in Australia have adopted the World Health Organization's definition of IPE and also recognized specific competencies to reflect the content of IPE. ${ }^{1,5}$ While assessment of the competencies needs further consideration, the Australian Health Professions Accreditation Council's Forum (HPACF) proposes that there is a need for cross profession accreditation and/or for one accreditation authority to recognize the quality assurance and accreditation activities of other accreditation authorities. ${ }^{5}$ In addition, HPACF and the Australian Health Practitioner Regulation Agency (AHPRA) suggest that in order to understand and address the barriers and opportunities to better organize and plan the delivery of IPE in Australia, innovative methods of interprofessional learning, including regulatory means for cross professional supervision need to be supported.

Consequently, HPACF supports education providers to develop and evaluate IPE practices, including curricula integration, simulation preparation, outcome measurement, and the transfer of learning to clinical practice. ${ }^{5}$ The School of Health and Human Sciences at Southern Cross University provided an IPE clinical placement opportunity in primary health settings (rural/remote and international) for undergraduate students (speech pathology, occupational therapy, podiatry and nursing) enrolled in a unit of study underpinned by Primary Health Care and Health Promotion.

The aim of this study was to evaluate the impact of an IPE clinical placement in a primary healthcare setting on students' perceptions of interprofessional education

\section{METHODS}

\section{IPE Primary Healthcare Clinical Placements}

The IPE clinical placements were offered to all undergraduate students at Southern Cross University enrolled in degrees in the disciplines of occupational therapy, speech pathology, podiatry and nursing, concurrently undertaking a unit of study in primary health care and health promotion. The nursing students were in the second year of their degree and the allied health students were in their second, third and fourth years. The placements aligned with primary healthcare and health promotion units of study, in which lectures and tutorials introduced students to the primary healthcare model, the principles of health promotion, as well as health education and the importance of improving a patient's health literacy. The IPE placements were advertised in March and the recruitment process commenced in April. Students were invited to express interest in the placement via a short application and were selected for the IPE experience based on academic achievement (grade point average) and quality of responses to short-answer questions. Feedback on performance during previous clinical placement experiences was also considered. Placements were conducted in primary healthcare settings across three rural/remote towns in New South Wales, Australia and two rural villages in Southeast Asia (Cambodia and Vietnam). Placements spanned three to six weeks, and included three to twenty students, from at least three different disciplines at each site. Students participated in three pre-placement workshops, aimed to increase the students' understanding of placement expectations, student and facilitator roles and responsibilities, as well as orientation to the placement sites. Because of time constraints of learning activities, students did not have the opportunity to engage in collaborative education prior to the IPE clinical placement.

While on the IPE placement, students worked in interprofessional teams to develop and implement health promotion strategies. The structure of the IPE placement was underpinned by the principles of primary health care, including community participation in defining and implementing health needs and health promotion activities. ${ }^{6}$ Daily meetings and debriefs to discuss challenges, opportunities, and community health needs were conducted with experienced university clinical facilitators. Consequently, a wide variety of health education was delivered, including benefits of exercise, menstruation hygiene, hand hygiene, nutrition, sun safety, oral hygiene, eye care, communication milestones education, social skills development, swallowing and mealtime management. Students were also required to develop a health promotion initiative that involved an interprofessional team working on intersectoral collaboration; the idea was to develop an integrated sustainable ongoing placement program. Following the conclusion of 
the placement, students provided a post-placement reflection on the health promotion strategies they implemented and reflected on their experience of working in an interprofessional team.

\section{Ethics}

Ethical approval was granted by the Southern Cross University Human Research Ethics Committee (ECN-17-178) and methods conformed to the guidelines of the National Statement on Human Experimentation. ${ }^{14}$ Participants were emailed the participant information statement and indicated informed consent by completing an online consent form.

\section{Participants}

All students enrolled in the IPE placements were invited to participate in the evaluation study; they were informed that participation in the study was not mandatory for completion of the placement.

\section{Design}

This was a longitudinal exploratory pilot study; students were invited to complete a validated questionnaire in the week prior to placement commencement (Time 1; T1), and in the week following IPE placement completion (Time 2; T2).

\section{Procedure}

Students who completed the questionnaires at both time points ( $\mathrm{T} 1$ and $\mathrm{T} 2$ ) via online SurveyMonkey were included in the study analysis. Students were emailed a link to the online survey by a research assistant. ${ }^{7} \mathrm{~A}$ reminder email to complete the survey was posted to students 2 days before and on the due date.

\section{Materials}

The Interdisciplinary Education Perception Scale (IEPS), a validated and reliable tool, assessed students' perceptions toward IPE. ${ }^{8}$ The IEPS, an 18-item tool utilizing a 5-point Likert scale, gauges professionally oriented perceptions and affective domains for participants in IPE programs. Four subscales include 1) perceived competency and autonomy of own profession including how others perceive your profession, 2) perceived need for interprofessional cooperation, 3) perception of actual interprofessional cooperation, and 4) participant understanding of their/others' roles in interprofessional cooperation. Questions explore students' perceptions of their own profession's capabilities, contributions, collaboration with others, and confidence of others' competence. The tool has previously been utilised to assess the effect of IPE experiences on undergraduate healthcare students. ${ }^{9-11}$ In this tool, the subscale and total scores are summed with higher scores indicating more positive perceptions of IPE.

\section{Data Analysis}

Quantitative data was cleaned and analyzed in SPSS version $22 .{ }^{12}$ Dependent group $t$-tests and Wilcoxon signed-rank test (for non-parametric data) were used to examine within-group differences from T1 to T2. Missing values $(n=4)$ were prorated with participant subscale means. As this was a small pilot program, we did not correct for multiple comparisons as this can be overly conservative; however, for completion, Bonferroni correction for multiple comparisons was considered and relevant significance levels are presented. ${ }^{13}$

\section{RESULTS}

\section{Demographics}

Sixty-three students were invited to participate and a total of 83 completed questionnaires were returned (43 pre, and 40 postplacement). The final sample included 19 students who completed both a pre, and post-placement questionnaire; demographics for these students are presented in Table I. The pre-placement questionnaire was undertaken the week prior to placement, and the post-placement questionnaire was completed in the week following the completion of placement. 
Table 1. Participant Demographics

\begin{tabular}{|l|l|l|}
\hline Demographic & $(\boldsymbol{n}=\mathbf{1 9 )}$ & $\boldsymbol{n}(\%)$ \\
\hline Age range, M(SD) years & & $19-46, \mathrm{M}=30, \mathrm{SD}=8.1$ years \\
\hline Gender & Female & $15(79 \%)$ \\
\hline & Male & $4(21 \%)$ \\
\hline Discipline & Nursing & $16(84 \%)$ \\
\hline & Occupational Therapy & $2(11 \%)$ \\
\hline & Podiatry & $1(5 \%)$ \\
\hline & Speech Pathology & $0(0 \%)$ \\
\hline Student Type & Domestic & $18(95 \%)$ \\
\hline & International & $1(5 \%)$ \\
\hline Placement Type & Rural/remote & $7(37 \%)$ \\
\hline & International & $12(63 \%)$ \\
\hline Previous IPE Experience & Yes & $2(11 \%)$ \\
\hline & No & $17(89 \%)$ \\
\hline
\end{tabular}

Note: percentages may not sum to 100 because of rounding.

*It was not in the scope of this pilot to determine what constituted previous IPE experience

\section{Perception of Interdisciplinary Education (IEPS)}

Perceptions of IPE appeared to increase over the course of the study; mean scores for T1 and T2, including significance tests for change over time, can be seen in Table II.

Table 2. Interdisciplinary Education Perception Scale (IEPS)

\begin{tabular}{|l|l|l|l|l|}
\hline \multicolumn{1}{|c|}{ Scale Category } & Possible Range & \multicolumn{1}{|c|}{$\begin{array}{c}\text { Pre-placement } \\
\text { Mean(SD) }\end{array}$} & \multicolumn{1}{c|}{$\begin{array}{c}\text { Post-placement } \\
\text { Mean(SD) }\end{array}$} & $\begin{array}{c}\text { Sig. } \\
\text { p }\end{array}$ \\
\hline IEPS Competency \& Autonomy & $8-48$ & $40(4.9)$ & $42(5.3)$ & $.033^{*}$ \\
\hline IEPS Need for Cooperation & $2-12$ & $11(1.5)$ & $11(0.8)$ & .616 \\
\hline IEPS Actual Cooperation & $5-30$ & $25(2.8)$ & $26(3.5)$ & $.012^{*}$ \\
\hline IEPS Understanding Roles & $3-18$ & $12(2.8)$ & $14(2.8)$ & $.001^{* *}$ \\
\hline IEPS Total & $18-108$ & $87(10.1)$ & $93(10.3)$ & $.001^{\text {** }}$ \\
\hline
\end{tabular}

*Significant when $\mathrm{a}=0.05$

${ }^{* *}$ Significant after Bonferroni correction where $\mathrm{a}=0.01$

Results indicated overall perceptions of IPE significantly increased over the course of the IPE placement. There was a significant increase in the reported competency and autonomy and understanding of roles scores over time. There was no significant increase in the reported perception of need for interprofessional cooperation; however, there was a significant increase in actual interprofessional cooperation.

\section{DISCUSSION}

The aim of this pilot study was to evaluate the impact of an IPE clinical placement in a primary healthcare setting on students' perceptions of IPE.

This study supports previous research demonstrating the positive impact of an IPE placement in a primary healthcare setting by significantly improving and effecting changes to allied health and nursing students' perception of IPE. ${ }^{15-17}$ Over the course of the IPE placement, students' beliefs about their own competency and autonomy of their profession significantly improved, as did their beliefs about how other professions perceive them. There were no significant changes in students' beliefs about the need for interprofessional cooperation or dependency on other professions; however, there was a significant improvement in actual interprofessional cooperation which included working together, sharing resources, and regard for other professions. Students' understanding of their role in interprofessional cooperation improved, including the belief that other professions regard them highly, and that they, in turn, endeavour to understand capabilities and contributions of other professions. Students showed improved perceptions of interprofessional teamwork, including the benefits of shared-learning for effective teamwork and the need for positive relationships between professionals.

Interprofessional education is increasingly being introduced into undergraduate healthcare courses. However, it is often restricted to the classroom context rather than placement settings. ${ }^{18}$ As the IPE literature affirms, there are limitations to providing high- 
quality and sustainable interprofessional programs in an academic context. ${ }^{19}$ The clinical placement environment, provides students with unique opportunities for high quality interprofessional learning. ${ }^{20}$ This study has demonstrated that an IPE clinical placement in a primary healthcare setting is a valuable medium for delivering motivating interprofessional learning experiences. It can provide opportunity to practice teamwork skills and develop a deeper understanding of the roles, responsibilities and perspectives of other disciplines. ${ }^{20}$

In this study, students assisted in the delivery of health promotion programs in primary healthcare settings in rural/remote New South Wales and in Cambodia and Vietnam. Primary healthcare focuses on the integration and expansion of services that promote population health, disease prevention, and health promotion. By nature, primary healthcare and health promotion requires the collaboration of all health providers to capitalize on the health resources available to address illness within broad determinants of health. ${ }^{21}$ Primary healthcare settings, for example schools and community health, are underpinned by inter-sectoral models of working. Their services and programs have a long history of involving a wide range of different professions, sectors and volunteers. Consequently, interprofessionalism is central to everyday practice and generally less constrained by the hierarchies, power dynamics, and communication barriers between professions that have characterised clinical and hospital settings. ${ }^{20}$ Thus, in comparison to clinical settings, the primary healthcare context may be a particularly effective way for students to experience IPE, and interprofessional workplaces and structures.

Students in this pilot study had the opportunity to debrief daily with the IPE facilitator during their placement experience, encouraging students to reflect on the challenges and opportunities associated with working together in an interprofessional team. The IPE literature highlights the importance of providing debrief opportunities for students. Team meetings, observing other students in practice and shared discipline consultations have been found to result in successful strategies for interprofessional learning. ${ }^{22,23}$ For example, in a study where facilitated debriefing was compared with self-directed learning after simulated IPE clinical scenarios, it was found that debriefing was more effective, and the key importance of the facilitator in enabling effective interprofessional engagement was highlighted. ${ }^{24}$ Following the conclusion of the IPE placement, students developed a professional report where they reflected on the health promotion strategies they had implemented, as well as on their experience of working in an interprofessional team. Benefits to incorporating regular reflection into interprofessional learning processes using journals has been previously demonstrated. ${ }^{25}$ The provision of debrief opportunities, including team meetings and the use of post-placement reflection may have contributed to the positive education impact of the IPE placement.

While this IPE intervention elicited a positive impact on students' perception of IPE and their awareness and attitudes toward interprofessional practice, there were various "lessons learned" that can help improve the future design and delivery of IPE placements. Most of the pre-placement academic content that students were exposed to focused on health promotion and primary healthcare. Exposing students to comprehensive IPE theory, a comprehensive introduction to the core competencies of interprofessional teamwork, and workshop activities that focus particularly on interprofessional collaboration may strengthen students' preparation for their IPE placement experience and their perception of the need for interprofessional cooperation. Integrating interprofessional core competencies into the curriculum can support and improve the knowledge of professional roles and collaborative practice. ${ }^{26}$

Students participating in the program had limited opportunities to learn together in interprofessional teams prior to departure. The placement experience was a component of a separate unit for each discipline, which meant that the academic content was different for each professional group. According to the literature, it is beneficial for students to engage in IPE learning prior to their IPE placement experience. Lewis and Stone claim that effective IPE should involve students learning together in multi-professional groups as well as structured academic content centred on, and delivered through, teamwork and collaboration. ${ }^{27}$

Best practice methods for teaching IPE include seminars, workshops, and simulations. ${ }^{28}$ In their evaluation of an IPE clinical placement in the UK, O'Carroll et al explored the usefulness of scheduled workshops prior and during placement. ${ }^{20}$ Learning activities were delivered by an experienced IPE facilitator and involved discussing and comparing professional identities and exploring roles and responsibilities within the healthcare team. ${ }^{20}$ These sessions were shown to enhance interprofessional understanding, improve team communication skills, and develop perspectives from other professional points of view. ${ }^{20}$

Therefore, consistent with the literature, future IPE interventions could strengthen the integration of disciplines prior to placement so that students work together more collaboratively as interprofessional teams. This coordinated placement preparation would enable students from allied health and nursing disciplines to interact in shared learning spaces, which may enhance students' understandings of the capabilities and contributions of other professions, as well as assist them in developing strong team communication skills. Collaboration and teamwork are essential to delivering patient-centred care, therefore IPE opportunities need to be encouraged to continue as the students enter the workforce. 
Literature highlights the need for a package of interprofessional activities, rather than discrete primary healthcare placements. ${ }^{22}$ As Thistlethwaite states, multiple teamwork experiences and activities improve collaborative skills rather than a standalone activity or single exposure. ${ }^{29}$ The incorporation of IPE into ongoing programs, rather than appending it as an add-on or a short-term project, has been found to reinforce collaboration and communication skills. ${ }^{27}$ The literature also recognizes various process and contextual factors that impede the integration of IPE across the university health curriculum. In particular, organizational support from senior management and local IPE leaders has been regarded as paramount to the successful implementation and sustainability of IPE. ${ }^{30}$ According to international research, there persists a fragility of institutional support for IPE which threatens to undermine the longterm viability of IPE. ${ }^{31}$

The departmentalized structure of universities further hampers efforts to implement IPE. For most healthcare disciplines, IPE is a departure from their formal discipline-specific education. ${ }^{21}$ Healthcare professionals have been traditionally educated in relative isolation from one another with little understanding of the roles and responsibilities of other disciplines. ${ }^{21}$ The fragmented structure of universities is reflected in the traditional model of siloed teaching, which focuses on knowledge specialization by disciplinary fields. ${ }^{30}$ Research proposes that this sort of disconnect from other aspects of the core curriculum may prevent students from strengthening their IPE perceptions and skills. ${ }^{28}$ Fragmentation and the siloed model of teaching make coordination between different disciplines difficult. A practical barrier to IPE that derives from this linear and discipline-based thinking, is timetabling. Significant contextual factors that continue to impede IPE include difficulties associated with space and timetabling of learning activities. ${ }^{28}$

Ultimately, while the pilot program had significant positive impacts on students' perceptions of IPE, there are various "lessons learned" that can help inform the design, delivery and evaluation of future IPE programs. Implementing these changes could strengthen long-term IPE sustainability.

\section{LIMITATIONS}

The voluntary nature of the placement may have affected the results of the research. While in general, IPE participation is a voluntary activity, there is the potential for selection bias. ${ }^{22,28, ~ I n ~ a d d i t i o n, ~ t h e s e ~ v o l u n t e e r ~ s t u d e n t s ~ w e r e ~ a l r e a d y ~ e n t h u s i a s t i c ~ a b o u t ~}$ IPE, which meant that they were more likely to respond positively to the IPE learning experience. Indeed, students who self-select for IPE are regarded as motivated to learn in a collaborative manner with students from other disciplines. ${ }^{28}$ Another limitation to the study was the reliance on self-reporting; the extent of actual change to collaborative attitudes, knowledge, and skills may be less than the perceived change that was reported by students. ${ }^{28}$

Participation in the study was voluntary, and out of the sixty-three students who participated in the placement, only nineteen completed both the pre- and post-placement questionnaires. A response rate of $30 \%$ from students for online surveys is considered average. ${ }^{32}$ However, of the nineteen completed questionnaires, 16 were from nursing students and three from allied health students (Occupational Therapy and Podiatry). No speech pathology students completed both the pre- and post-placement surveys. While student perceptions' of IPE have been reported to differ by health profession, and allied health and nursing students have reported consistent positive teamwork attitude change, the uneven distribution of professional groups is a major limitation of the study. ${ }^{23} \mathrm{~A}$ research assistant, independent of the academic disciplines, was responsible for the distribution and return of the surveys. Nonetheless, individual academics associated with the professional groups may also have reminded students to complete the survey. Familiarity with the research has been reported to improve survey return rates. ${ }^{33}$ Furthermore, students were invited to complete the survey one week prior to placement commencement and in the week following IPE placement completion. The review of communication, engagement, and follow-up methods to improve response rates in future IPE research is recommended. ${ }^{33}$ Only $21 \%$ of the student cohort were male, and while this gender imbalance is reflective of the nursing and allied health student population, future research should explore gender experience.

\section{CONCLUSION}

The IPE placement program in a primary healthcare setting significantly improved and affected changes to allied health and nursing students' perception of IPE. This pilot program warrants further development and research, including whether the collaboration and teamwork skills obtained during the IPE experience are transferrable to future professional practice.

\section{CONFLICTS OF INTEREST}

The authors declare no conflicts of interest; this manuscript does not regard a commercial product. 


\section{REFERENCES}

1. World Health Organization. Framework for action on interprofessional education \& collaborative practice. 2010. Retrieved from http://www.who.int/hrh/resources/framework_action/en/

2. McKimm J, McLean M. Developing a global health practitioner: Time to act? Medical Teacher. 2011;33(8):626-631. doi.org/10.3109/0142159X.2011.590245

3. Anderson ES, Ford J, Kinnair DJ. Interprofessional Education and Practice Guide No. 6: Developing practice-based interprofessional learning using a short placement model. Journal of Interprofessional Care. 2016;30(4):433-440.

4. Health Professions Accreditation Councils' Forum. Workshop Report: Collaborating for Patient Care - Interprofessional Learning for Interprofessional Practice. 2015. Retrieved from https://www.coaghealthcouncil.gov.au/Projects/IndependentReview-of-NRAS-finalised

5. Health Professions Accreditation Councils' Forum. Independent Review of Accreditation Systems within the National Registration and Accreditation Scheme for health professions. 2017. Retrieved from https://www.coaghealthcouncil.gov.au/Projects/Accreditation-Systems-Review

6. World Health Organisation. (1986). Ottawa Charter for Health Promotion: First International Conference on Health Promotion Ottawa, 21 November 1986. Retrieved from https://www.healthpromotion.org.au/images/ottawa charter_hp.pdf

7. SurveyMonkey Inc. SurveyMonkey. 2017. San Mateo, California, USA.

8. Luecht RM, Madsen M,Taugher M, Petterson B. Assessing professional perceptions: Design and validation of an interdisciplinary education perception scale. Journal Allied Health. 1990;19(2):181-191.

9. Goelen G, De Clercq G, Huyghens L, Kerckhofs E. Measuring the effect of interprofessional problem-based learning on the attitudes of undergraduate health care students. Medical Education. 2006;40(6):555-561. doi.org/10.1111/j.13652929.2006.02478.x

10. Becker E, Godwin E. Methods to improve teaching interdisciplinary team work through computer conferencing. Journal of Allied Health. 2005; 34(3):169-176.

11. McFadyen AK, Webster VS, Maclaren WM, O'Neill MA, Interprofessional attitudes and perceptions: results from a longitudinal controlled trial of preregistration health and social care students in Scotland. Journal of Interprofessional Care. 2010;24(5):549-564. doi.org/10.3109/13561820903520369

12. IBM Corp. (2013). IBM SPSS Statistics for Windows, Version 22.0. Armonk, NY: IBM Corp.

13. Perneger TV. What's wrong with Bonferroni adjustments. British Medical Journal. 1998;316(7139):1236.

14. National Health and Medical Research Council of Australia. National statement on ethical conduct in human research. 2007. Retrieved from https://www.nhmrc.gov.au/guidelines-publications/e72

15. Howell DM, English L, Page JL. The Rockcastle Project: A Case Study of Interprofessional Clinical Education and Practice in a Rural Medical Center. The Internet Journal of Allied Health Sciences and Practice. 2011;Apr 01;9(2), Article 6.

16. Williams B, McCook F, Brown T, Palmero C, McKenna L, Boyle M, et al. Are Undergraduate Health Care Students 'Ready' for Interprofessional Learning? A Cross-Sectional Attitudinal Study. The Internet Journal of Allied Health Sciences and Practice. 2012:Jul 01;10(3), Article 4.

17. Goreczny A, Bednarek ML, Hawkins SR, Hertweck ML, Schreiber J, Sterrett SE. Assessing Self-Reported Interprofessional Competency in Health-Care Education: Impact of New Curriculum. The Internet Journal of Allied Health Sciences and Practice. 2016;Jul 20;14(3), Article 11.

18. Nasir J, Goldie J, Little A, Banerjee D, Reeves S. Case-based interprofessional learning for undergraduate healthcare professionals in the clinical setting. Journal of Interprofessional Care. 2017;31(1):125-128. doi.org/10.1080/13561820.2016.1233395

19. Freeth D, Hammick M, Reeves S, Koppel I, Barr H. Effective Interprofessional Education: Development, Delivery \& Evaluation. 2005;Oxford: Blackwell.

20. O'Carroll V, Braid M, Ker J, Jackson C. How can student experience enhance the development of a model of interprofessional clinical skills education in the practice placement setting? Journal of Interprofessional Care. 2012;26(6):508-510. doi.org/10.3109/13561820.2012.709202

21. Curran V, Sargeant J, Hollett A. Evaluation of an interprofessional continuing professional development initiative in primary health care. Journal of Continuing Education in the Health Professions. 2007;27(4):241-252. doi.org/10.1002/chp.144

22. Kent $F$, Keating J. Interprofessional education in primary health care for entry level students - A systematic literature review. Nurse Education Today. 2015;35(12):1221-1231. doi.org/10.1016/j.nedt.2015.05.005

23. Renschler L, Rhodes D, Cox C. Effect of interprofessional clinical education programme length on students' attitudes towards teamwork, Journal of Interprofessional Care. 2016;30(3):338-346. doi.org/10.3109/13561820.2016.1144582

24. LeFlore JL, Anderson M. Alternate educational models for interdisciplinary student teams. Simul Healthc. 2009. Fall;4(3):135-42. doi: 10.1097/SIH.0b013e318196f839 
25. Richardson R, Letts L, Childs A, Semogas D, Stavness C, Smith B, Guenter D, Price D. Development of a community scholar program: an interprofessional initiative. J Phys Ther Ed. 2010. 24:37-43.

26. Bierwas DA, Rogers O, Taubman B, Kroneberger L, Carroll H, Enking P. Developing Clinical Faculty Understanding of Interprofessional Education: An Inter-institutional, Interprofessional Approach. The Internet Journal of Allied Health Sciences and Practice. 2017;Oct 03;15(4), Article 9.

27. Lewis B, Stone N. Shaping a sustainable interprofessional education program. Focus on Professional Education: A MultiDisciplinary Journal. 2007;8(3):27-46.

28. Reeves S, Perrier L, Goldman J, Freeth D, Zwarenstein M. Interprofessional education: effects on professional practice and health-care outcomes. Cochrane Database Syst Rev. 2013;28(3). DOI: 10.1002/14651858.CD002213.pub3.

29. Thistlethwaite J. Interprofessional education: a review of context, learning and the research agenda. Medical Education. 2012; 46(1):58-70. doi.org/10.1111/j.1365-2923.2011.04143.x

30. Reeves S, Fletcher S, Barr H, Birch I, Boet S, Davies N, McFadyen A, Rivera J, Kitto S. A BEME systematic review of the effects of interprofessional education: BEME Guide No. 39, Medical Teacher. 2016;38(7):656-668. doi.org/10.3109/0142159X.2016.1173663

31. Da Silva J, Peduzzi M, Orchard C, Leonello V. Interprofessional education and collaborative practice in Primary Health Care, Journal of School of Nursing. 2015;49(2):15-23. doi.10.1590/S0080-623420150000800003

32. Nair $\mathrm{CH}$, Adams P, Mertova P. Student Engagement: The Key to Improving Survey Response Rates, Quality in Higher Education. 2008;14:3, 225-232, DOI: 10.1080/13538320802507505

33. Saleh A, Bista K. Examining factors impacting online survey response rates in educational research: perceptions of graduate students, Journal of Multidisciplinary Evaluation. 2017;13:29, 63-74 